\title{
Age determination in asylum seekers: physicians should not be implicated
}

\author{
Pieter J. J. Sauer ${ }^{1}$ - Alf Nicholson ${ }^{2}$ - David Neubauer ${ }^{3}$ • \\ On behalf of the Advocacy and Ethics Group of the European Academy of Paediatrics
}

Received: 20 January 2015 /Revised: 4 August 2015 / Accepted: 9 August 2015 /Published online: 18 September 2015

(C) Springer-Verlag Berlin Heidelberg 2015

\section{Introduction}

Every year asylum seekers come to Europe. Around $4 \%$ of these are, according to their testimony, minors. Because the regulations for admitting or refusing to enter the country are different between minors and adults, governments are eager to ascertain the age of the asylum seekers who testify to be minor. The help of physicians is sought to determine the age of these individuals. Date of birth and chronological age but also biological age are determinants of how individuals can participate in, or are treated by, the society in which they live. The fact that evidence of age is fundamental to the realisation of rights and needs in society is recognised in Article 7 of The United Nations Convention on the Rights of the Child, which states that "The child shall be registered immediately after birth" [18]. Unfortunately, it has been estimated that around 51 million births go unregistered each year in developing countries, mainly in South Asia and sub-Saharan Africa [19]. Even when a birth has been registered, the individual

Communicated by Jaan Toelen

Revisions received: 28 May 2015 / 05 August 2015.

Pieter J. J. Sauer

p.j.j.sauer@umcg.nl

Alf Nicholson

Norma.mceneaney@cuh.ie

David Neubauer

david.neubauer@mf.uni-lj.si

1 Department of Paediatrics, Beatrix Children Hospital/UMCG, Hanzeplein 1, 9700RB Groningen, The Netherlands

2 Department of Paediatrics, Children's University Hospital, Dublin 1, Ireland

3 Department of Child, Adolescent and Developmental Neurology, University Children's Hospital, Ljubljana, Slovenia may lose the documentation and have no way of replacing it, particularly in times of upheaval such as war and social unrest. The unfortunate geographical coincidences of incomplete birth registration rates, wars and poverty mean that refugees and asylum seekers often possess no evidence of age.

Worldwide, in 2008, there were approximately 827,000 asylum seekers, $44 \%$ of whom were children [21]. Unaccompanied or separated children formed $4 \%$ of asylum claims. Age is a key determinant of how an individual is handled in such circumstances and may be the deciding factor in the success or failure of an asylum application. For children, it also defines access to education and healthcare.

Three important aspects must be considered regarding age determination in cases when the age of an asylum seeker is in doubt.

\section{Ethical questions}

Is there any justification that physicians are involved in the age determination of an asylum seeker of whom the age is in doubt, when there is no medical reason to perform such investigation? Is this dependent on the reliability and invasiveness of the test? Is consent of the individual needed, and will consent be given freely, without any pressure? What will the position of the minor be when he/ she refuses consent for any procedure? Does the physician undermine the confidentiality of the patient-doctor relationship by giving his opinion to the legal authorities?

2. Medical questions

Are there methods that reliably can estimate the age of the asylum seeker, what is the estimated error? How invasive is the investigation?

3. Legal questions

What is the legal basis to use a fixed cut-off point like 18 years to differentiate between a minor and an adult? Is an age of 18 years, established for children growing up in 
a western society, also applicable for a minor growing up under very different and perhaps severely threatening conditions? Should the best interest of the minor prevail above other legal rules? Should mental/psychological maturity not be a more valid criterion than chronological/ physical age?

As the answer to the medical issues might influence the other issues as well, this aspect will be discussed first.

\section{Medical issues}

The influx of young individuals, who are applying for the international protection in the context of refugee status and asylum, with no valid proof of identity has led to a perceived need for accurate methods of estimating age. There may, or may not, be a direct benefit to the individual in accurate age estimation. While the major challenge to societies is ensuring the appropriate and just handling of refugees and asylum seekers, there are other challenges. The increase in trafficking of children, notably by the sex industry, adds a further problem related to age identification. It has been estimated that there were 1.2 million child trafficking victims in 2000 [9]. Traffickers may claim that children are older than their true age, and the victims are intimidated into corroborating the claims.

The relevant medical issues are (1) How reliable are the tests to assess chronological age? and (2) Is it ethical to perform these measurements if the person does not benefit from this?

Wrist radiographs and clavicle computerized tomography (CT) can be used to assess maturity as can dental assessment. However, both dental and skeletal age methods are limited by their accuracy, with established error ranges of plus or minus more than 12 months.

The most widely used radiological means of age assessment is the radiograph of the left hand. During skeletal development, the bones of the hands and the wrist undergo predictable changes that are associated with chronological age, specifically in the process of epiphyseal ossification and in size and form. Skeletal development of the hand is typically complete at 17 years in females and 18 years in males [13, 14].

Reference atlases of hand development have been devised, against which an individual image can be judged. (e.g. widely used hand atlas of Greulich and Pyle [4]) It is important to recognise that, assuming a normal distribution of data, \pm 1 standard deviation indicates that approximately $68 \%$ of individuals will lie within this range. The range for 95 or $99 \%$ confidence intervals will obviously be wider. Where bone age estimation is being used as a key determinant of how an individual is handled in a legal context, such inaccuracy is wholly unacceptable. Likely, subjects for age estimation (asylum seekers) most commonly originate from sub-Saharan Africa [20] and appropriate reference data are not available. The low socioeconomic status and malnutrition that may coincide with refugee status can delay skeletal maturation $[5,8]$. No studies appear to have been performed in populations from which those requiring age estimation are likely to originate.

Dental development on panoramic radiographs is used as a method of chronological age estimation. The effective dose of radiation is of a similar order to that associated with a hand radiograph $[10,17]$. Different teeth form at different ages, and at any particular age of childhood or adolescence, characteristic stages of formation of the dentition can be seen on radiographs. The process of tooth formation encompasses approximately the first 20 years of life. As dental development is in most cases not finished at 18 years, it cannot be used to differentiate between ages below or above 18 years. The third molars might develop up to the age of 30 years [11]. Using third molar development for age determination is hampered by a large standard deviation in the normal development and by possible ethnic differences in maturation. In the context of refugees and asylum seekers, dental development, including the development of the third molar, has never been studied in different ethnic groups and no applicable reference data are available $[2,10]$. Thus, the absence of applicable reference data increases doubt over the accuracy of age estimations based on tooth development.

Recently, MRI of the clavicle has been advised as method to determine the age of a person. This method however has the same problem of all other investigations, a large intra-individual variation. Moreover, a MRI investigation might be very traumatic for asylum seekers as many of them might have a posttraumatic stress syndrome. Having a MRI made is a rather frightening and stressful event.

Any method of age estimation should involve methods that are scientifically established for which the accuracy and confidence intervals are known. As racial, sex and possibly socioeconomic differences exist in dental and skeletal development, the correct reference data should be available and the validity of the method established for the individual case. All methods of bone and dental maturity are based on probability calculations. These calculations assume a random distribution of estimates. In most European countries, age assessments are made only when the age is disputed. Since there is a clear, but unknown, correlation between the physical appearance and measures of age like X-rays, the random distribution is clearly not relevant.

While the ideal situation would be to identify a diagnostic test that accurately determines chronological age, no such test exists. In reality, age can only be estimated by measuring or observing features that are associated with chronological age. Features include height and weight measurement, signs of sexual maturity and observation of behaviour. 
Observation of behaviour has been advised as method to determine if an asylum seeker is "mature" [1]. The Royal College of Paediatrics and Child Health in the UK emphasize in their guidelines the relevance of a child's social history as part of the assessment. They recommend that age assessment is carried out as a holistic evaluation, including "narrative accounts, physical assessment of puberty and growth and cognitive, behavioural and emotional assessments" [12]. These assessments have been criticized because the procedures are rarely well described, how a judgement is reached is not clear and personnel with expertise in child development, like child psychologists and paediatricians are seldom involved [6]. Moreover, asylum seekers are being observed while they are not aware of this observation.

For all these methods, accuracy decreases with an increase in chronological age, becoming less accurate in adolescents than in younger children, and even less accurate in adults than in adolescents. There is some element of inter-observer variability in addition to this. In asylum seekers, the question frequently posed is "is this subject 18 years or above?" rather than age determination under 10 years. All estimates suffer from broad normal ranges. Furthermore, concurrent diseases and malnutrition often delay maturity. While psychosocial assessment provides important indications of maturity, it is influenced by cultural/ethnic background and personnel experience of the individual. Poor socioeconomic status and being prematurely matured by their life experience is a common feature for refugees and others for whom age estimation is required $[7,15,16]$.

Without an accurate method of age determination, asylum seekers, illegal immigrants and victims of trafficking in human beings fail to receive appropriate care and support.

EU countries face significant challenges in identifying the age of individuals who have no valid proof of birth date or identity document. Article 3 of the European Council Directive 97/43 states that "special attention shall be given to the justification of those medical exposures where there is no direct health benefit for the person undergoing the exposure and especially for those exposures on medico-legal grounds" [3]. This important principle is particularly relevant in the case of age estimation, where the affected individuals are likely to be children and adolescents, whose risks from x-ray exposure are greater than those of adults.

Finally, the asylum seekers are not patients and therefore physicians have no right to violate the privacy of the individual. Participation in the process of age determination might also interfere with the present and future patient-doctor relation $[6,17]$

\section{Ethical aspects}

Determination of the age of an asylum seeker who testifies to be a minor can have far stretching consequences. When he/she is judged to be a minor, they will not be returned to their country of origin or to another state, but be allowed to stay in the country where asylum is asked, at least till adult age is reached. The question is when adult age is reached in asylum seekers. Individuals who might have experienced important happenings in their life might not have reached maturity in the psychological sense at 18 years. In their behaviour, they still might be minors. Is it correct to use as definition of maturity the age of 18 years as used for people grown up in Western Europe? What might have been the impact of malnutrition, poverty, disasters and stressful factors on the maturational process of an adolescent? Can adulthood be defined with only an age limit?

The next question is if physicians should be part of the legal system deciding about the fate of asylum seekers claiming to be a minor. First, granting asylum is a legal and political issue and there is no medical reason for physicians to be involved. The health of the individual is not at stake. Secondly, can a physician be forced by a government to be involved? When a physician is participating is he/she violating the Oath of Hippocrates? Is the physician responsible for physical and/or psychological damage of the adolescent when he or she is returned to the country of origin, based on the opinion of the physician?

The next issue is getting informed consent. Obtaining a valid informed content presents a considerably challenge. Language and cultural barriers, inability to understand what might entail may be substantial and individuals may often be traumatized from past experiences. Furthermore, the validity of consent from an unaccompanied child in such circumstances must be doubted. The basic requirement of a consent procedure, that consent is given completely without any pressure, can be doubted.

Assessing age might be a benefit for children who are classified, based on the investigations as minors. They will receive shelter in the respective countries. Is this a reason to cooperate with legal authorities and conduct these investigations? Also, when paediatricians are not involved, other physicians with much less expertise in child development might be involved in these determinations. This might increase the risk of wrong assessments. Both arguments do not seem to justify the involvement of paediatricians. In contrast, paediatricians should use their influence to convince other medical specialists to refrain from being involved in these determinations.

A final ethical issue is how physicians may convey the results of the examinations to legal authorities. It might be difficult for legal authorities to realize that, when an estimated age of 18 years is reported, this means that the real age is somewhere between at least 17 and 19 years. Based on the uncertainty of the measurement should the age never be reported as one number, but only as an age range. Altogether, there are important ethical reasons why physicians should not be involved in the age determination process. 


\section{Legal aspects}

According to International Conventions, in all decision involving children and adolescents, the "best interest of the child" must prevail. The minor is not asking asylum without important reasons. Either they did not feel safe enough in their home country, or the parents have send for whatever reason the adolescent to Europe. In both cases, the best interest of the child is to find shelter in Europe. Secondly, when arriving in Europe and particularly without proper documentation in support of their stated age, they are in an extreme fragile position. When they are asked to participate in a procedure to determine their age, they are in such a dependent position, that they cannot refuse. Refusing to participate in such investigations might negatively influence the chance to obtain a visa. The option to appeal to the results also is extremely difficult for these individuals. There are therefore important legal obstacles to the present procedures of age determination in asylum seekers stating that they are minors.

A way forward might be to move away from the idea to assess the chronological age of the individual and instead to consider the need for support. Decisions should be made on the needs of the individual, not on the assumed chronological age.

In summary, it is clear that all methods of radiological age estimation (dental and skeletal) can provide an estimation of age, but there are substantial confidence intervals for the estimated age, especially in older children, and adequate reference data are frequently unavailable. Secondly, it is questionable of one, simple age limit is appropriate for all asylum seekers who are stating they are minors. Third, the consent procedure will, frequently, not be in accordance with international legally binding standards. Finally, there is no guarantee that decisions made are in the best interest of the adolescent, a requirement contained in international conventions [19].

The scientific uncertainty and ethical concerns surrounding radiological age estimation practices have led influential professional medical organizations. The British Royal College of Paediatrics and Child Health have stated that: "there is no single reliable method for making precise estimates. The most appropriate approach is to use a holistic evaluation, incorporating narrative accounts, physical assessment of puberty and growth, and cognitive, behavioural and emotional assessments" [12]. The British Royal College of Radiologists has advised its members that X-rays should only be used in cases of clinical need and that requests for radiography solely for age determination were unjustified. The French Academy of Medicine, the French National Ethic Committee and the Dutch National Society of Physicians also have advised its members that physicians should not be involved in age determinations in asylum seekers stating they are minors, given all medical, ethical and legal aspects.

\section{Conclusion}

The European Academy of Paediatrics strongly recommends all paediatricians in Europe not to participate in the process of age determinations in minor asylum seekers stating they are minors. It also recommends all paediatricians to convey this opinion to all other physicians. All physicians should let the representatives in their countries know that they oppose the asylum Procedures Directive (2005/85/EC) according to which the member states may use medical examinations to determine age in relation to the procedure of an asylum application.

Competing interests None declared.

The authors declare to have not received specific grant from any funding agency in the public, commercial or not-for-public sectors.

Authors Contributions All authors equally contributed in writing this manuscript

\section{References}

1. Berger E, Friedrich M, Kaya M. Psychosocial Age Assessment (2006) In: Resource Book for Enforcement Officers on Good Practices in Combating Child Trafficking. Vienna: International Organization for Migration

2. Cote S, Geltman P, Nunn M, Lituri K, Henshaw M, Garcia RI (2004) Dental caries of refugee children compared with US children. Pediatrics 114:e733-740

3. European Commission (2007) Council directive 97/43/Euratom of 30 June 1997 on health protection of individuals against the dangers of ionising radiation in relation to medical exposure. European Commission, Luxembourg

4. Greulich WW, Pyle SI (1959) Radiographic atlas of skeletal development of the hand and wrist. Stanford University Press, Stanford CA

5. Himes JH (1978) Bone growth and development in protein-calorie malnutrition. World Rev Nutr Diet 28:143-187

6. Hjern A, Brendler-Lindqvist M, Norredam M (2012) Age assessment of young asylum seekers. Acta Paediatr 101:4-7

7. Husband J (2007) Letter: Planning Better Outcomes and Support for Unaccompanied Asylum Seeking Children. (2007). http://www. rcr.ac.uk/docs/general/pdf/AsylumseekersRCRfinalresponse.pdf (accessed 28/1/2011)

8. Introna F, Campobasso CP (2006) Biological vs legal age of living individuals. In: Schmitt A, Cunha E, Pinheiro J (eds) Forensic anthropology and medicine complementary sciences from recovery to cause of death. Humana Press, Totowa NJ

9. IPEC (2009) Training manual to fight trafficking in children for labour, sexual and other forms of exploitation. International Labour Office, International Programme on the Elimination of Child Labour (IPEC), Geneva

10. Ludlow JB, Davies-Ludlow LE, White SC (2008) Patient risk related to common dental radiographic examinations: the impact of 2007 International Commission on Radiological Protection recommendations regarding dose calculation. J Am Dent Assoc 139: $1237-1243$ 
11. Mincer HH, Harris EF, Berryman HE (1993) The ABFO study of third molar development and the use as an estimator of chronological age. J Forensic Sci 38:379-390

12. Royal College of Paediatrics and Child Health (2009) Policy: College statement on the role of paediatricians in the age assessment of unaccompanied young people seeking asylum, http://www. rcpch.ac.uk/Policy (accessed 27/1/2011)

13. Schmeling A, Baumann S, Schmidt S, Wernecke K-D, Reisinger W (2006) Reference data for the Thiemann-Nitz method of assessing skeletal age for the purpose of forensic age estimation. Int J Legal Med 120:1-4

14. Schmeling A, Reisinger W, Geserick G, Olze A (2006) Age estimation of Unaccompanied minors Part I. General considerations. Forensic Sci Int 159S:S61-S64

15. Schmeling A, Grundmann C, Fuhrmann A, Kaatsch HJ, Knell B, Ramsthaler F, Reisinger W, Riepert T, Ritz-Timme S, Rösing FW, Rötzscher K, Geserick G (2008) Criteria for age estimation in living individuals. Int J Legal Med 122:457-460
16. Singh HK, Scott TE, Henshaw MM, Cote SE, Grodin MA, Piwowarczyk LA (2008) Oral health status of refugee torture survivors seeking care in the United States. Am J Public Health 98:2181-2182

17. Thevissen pw, Kvaal SI, Dierikx K, Willems G (2012) Ethics in age estimation of unaccopanied minors $30: 85-102$

18. United Nations. Convention on the Rights of the Child. November (1989) Adopted and opened for signature, ratification and accession by General Assembly resolution 44/25 of 20

19. UNHCR (1997) Guidelines for policies and procedures in dealing with unaccompanied children seeking asylum . Geneva: Office of the United Nations High Commisioner for Refugees . http://www. unhcr.org/refworld/pdfid/3ae6b3360.pdf

20. UNHCR (2009) Global Trends: Refugees, Asylum-seekers, Returnees, Internally Displaced and Stateless Persons. Field Information and Coordination Support Section (FICSS), Division of Operational Services. UNHCR, Geneva

21. UNICEF (2007) Progress for Children. A World Fit for Children Statistical Review. New York:United Nations Children's Fund 